\title{
Letters
}

\section{Pressure ulcer and amyloidosis}

I read with interest the clinical case of the month by BieringSorensen et al. (Spinal Cord (1997) 35, 641-646.

I note an all too familar story of a young motorcyclist who sustained a complete spinal cord lesion and who clearly would not accept his disability and has inflicted sores upon himself.

The late Professor Sir Ludwig Guttmann described this as being 'physiological suicide'.

The presentation and discussion is largely devoted to the surgical mechanics of attempting to deal with multiple severe pressure sores involving joints.

What has to be appreciated is that such a sore can give rise to systemic disturbance, not only in the form of septicaemia, but can give rise to amyloid disease which can, in turn, prevent such sores healing due to the persistent leak of protein from the body in the urine and can lead to death from renal failure.

Amyloidosis has been recognised as a complication of sepsis from pressure sores in paraplegic patients since the days of Hilton Fagge (1876). ${ }^{1} \mathrm{He}$ described Amyloid disease secondary to chronic sepsis from pressure sores in patients with diseases of the spinal column.

Tribe \& Silver $^{2}$ reviewed 65 cases found in 174 necropsies conducted on patients dying in the National Spinal Injuries Centre between 1944 and 1964. This was a comprehensive survey of the causes of death in chronic paraplegics. In that series, the aetiological factors causing amyloidosis were a combination of chronic pressure sores, associated with underlying osteomyelitis and chronic urinary tract suppuration, agravated by calculosis.

No less than 60 of the patients had pressure sores

This work was continued at the National Spinal Injuries Centre between 1964 and $19800^{3,4}$ There were 215 deaths, amongst these there were 61 patients with amyloid disease. The major cause of sepsis was still large, chronic unhealed pressure sores. The diagnosis was easily made by creatinine clearance and $24 \mathrm{~h}$ urinary protein (which was invariably above $5 \mathrm{~g} / 24 \mathrm{hrs}$ ). The deaths occuring after 10 years were mainly due to chronic renal failure with almost invariably a protein leak of more than $5 \mathrm{~g} / 24 \mathrm{~h}$. This preceded death by no more than 3 years in $80 \%$ of cases.

Has this man developed amyloid disease?
What is his renal function, (in particular, the 24 hour urinary protein)?

If the urinary protein is raised, has there been a biopsy carried out?

JR Silver

Fellow of the Institute of Sports Medicine Consultant in Spinal Injuries

\section{References}

1. Fagge, CH. 1876. Specimens of lardaceous organs presenting some unusual characters with observations on the cases of lardaceous change in general. Trans. Path. Soc. Lond. 27: $324-$ 337.

2. Tribe, CR. \& Silver, JR. 1969. Renal failure in paraplegia, Pitman, Chapter 6, pages 54-90.

3. Baker, JHE., Silver, JR. \& Tudway, AJC. 1984. Late complications of pressure sores. CARE-Science and Practice, 3: $56-59$.

4. Baker, JHE., Rivett, JD., Silver, JR. \& Tudway, AJC. 1981. Amyloidosis in paraplegia: a clinico pathological correlation in Proceedings of the European Amyloidosis Research Symposium pages $97-100$.

\section{Reply from Dr F Biering-Sørensen and Dr JL Sørensen}

We do appreciate the letter from Dr. Silver drawing attention to the possible development of amyloid disease. This particular patient had, as described, urological problems including recurrent urinary stone. Seven years ago ureteroiliocutaneostomia was carried out. Urologically he has been followed with X-rays of the urinary tract, ultrasound and isotope renogrammes; the latest about a year ago. For the last 8 years function between the right and left kidneys has been $2 / 1$, and plasma creatinine values have always been normal. We have no measurements of 24 hour urinary protein, and haven't taken renal biopsies.

Fin Biering-Sørensen and Jens Lykke Sørensen Rigshospitalet Copenhagen University Hospital 25, Havnevej DK-3100 Hornbaek, Denmark 